\title{
CONSTRUCTION HAZARD AWARENESS AND CONSTRUCTION SAFETY KNOWLEDGE SHARING EPISTEMOLOGY
}

\author{
Rita Yi Man Li ${ }^{1 *}$, Kwong Wing Chau ${ }^{2}$, Weisheng Lü ${ }^{2}$, Daniel Chi Wing Ho ${ }^{3}$, Muhammad Shoaib ${ }^{4}, \mathrm{Li}$ \\ Meng ${ }^{5}$ \\ ${ }^{1}$ Hong Kong Shue Yan University, HKSYU Real Estate and Economics Research Lab, Hong Kong, China \\ ${ }^{2}$ The University of Hong Kong, Department of Real Estate and Construction, Hong Kong, China \\ ${ }^{3}$ THEi, Faculty of Design, Hong Kong, China \\ ${ }^{4}$ Department of Construction Engineering and Management, School of Civil and Environmental Engineering, National \\ University of Science and Technology, Islamabad 44000, Pakistan \\ ${ }^{5}$ School of Natural and Built Environment, University of South Australia, Adelaide, Australia \\ * Corresponding author
}

\begin{abstract}
Cognitive psychologists believe human error is the result of one or multiple catastrophes in three stages of the cognition process, namely hazard perception, recognition and decision making. Endsley's situation awareness theory proposed that when a person encounters a treacherous situation, precise and speedy decision making comprises matching or pattern recognition, which requires sophisticated schemata formation, and prototypical situations which ease the decision-making process. Hazard recognition largely depends on workers' ability to detect hazards. Thus, safety training is devoted to equipping workers with the skills needed to recognise and manage dangers. While mobile apps, Web 2.0 and the Internet of Things (IoT) are popular in everyday life communications, we speculate that safety awareness can be enhanced if these tools are popular in safety knowledge sharing among construction practitioners, emphasising the factors that influence their use, such as barriers, motivations, and psychological perspectives. The study found that the construction industry has not fully adopted these tools for knowledge sharing, and has not achieved considerable progress in safety awareness. Indeed, $13 \%$ of participants considered privacy concerns regarding the social media platforms, but this did not hinder their willingness to use said platforms. Similarly, the lack of knowledge of the older generation when it comes to using various platforms is a significant challenge for information sharing. The determination and willingness to learn have, however, led to an increase in the use of these platforms, with $54 \%$ of the articles dealing with knowledge sharing confirming this.

Keywords: construction safety, knowledge sharing, epistemology
\end{abstract}

\section{Introduction}

Cognitive psychologists consider human error to be a result of one or multiple failures in three stages of the cognition process: hazard awareness, recognition and decision making (Fang et al., 2018). Regarding hazard awareness, Endsley's situation awareness theory suggested that when a person encounters a hazardous condition, accurate and timely decision making comprises pattern recognition and matching, which necessitates sophisticated schemata formation, and archetypal knowledge that eases the decision-making process (Zeuwts et al., 2017). Musonda and Smallwood (2008) found that safety awareness was low in the construction industry. For example, $69.6 \%$ of the sites' workers in Botswana wore hard hats only, and $96 \%$ of the sites' workers did not wear eye protection. Indeed, hazard recognition mostly depends on workers' ability to spot hazards; low safety awareness and inadequate knowledge about safety lead to accidents (Li, 2015; Jeelani et al., 2017). Thus, safety training is needed to equip workers with the skills needed to recognise and manage hazards (Jeelani et al., 2017).

Despite this, the construction industry is seen as one of the major contributors to national economies around the globe. Le et al. (2014) suggested that economies cannot survive in the absence of the construction industry. Thus, many techniques have been introduced to reduce the number of incidents through knowledge sharing; indeed, said techniques are very diverse. Numerous studies have been conducted to reduce the incident rate by integrating the virtual or augmented reality technologies, serious gaming, database systems for automated safety and knowledge management (Li, Chan \& Skitmore, 2012).

Although many studies have been conducted to improve safety and provide education in construction, Fang et al. (2006) observed that less attention had been given to the sharing of this information. Revealing the data to the employees is not enough, as it must be shared consistently among them to prevent accidents on-site (Carbonari et al., 2011). Currently, knowledge management and sharing have become part of 
operating necessities in all industries (Nielsen \& Razmerita, 2014). Advancing technology eases communication, thereby reducing the need for face-to-face meetings ( $\mathrm{Li}, 2015)$. Easily accessible communication sites, such as WhatsApp, can host conferences irrespective of the geographical disparities of the participants. The use of Web 2.0, the internet of things (IoT), and mobile phone applications in the sharing of knowledge has become commonplace, especially among generation Y ( $\mathrm{Li}$ et al., 2018).

Nonetheless, the construction industry has not fully adopted these tools in knowledge sharing. Indeed, the construction industry has not achieved considerable progress in safety knowledge sharing and safety awareness. Therefore, the purpose of this research was to determine the extent of the popularity of Web 2.0, the IoT, and mobile applications in the sharing of safety knowledge among construction workers, emphasising the factors that influence their use, such as barriers, motivations, and psychological perspectives. This analytical study tested the hypothesis that the use of information technology to enhance knowledge sharing will help reduce the number of accidents on construction sites. The primary objective was to provide information to successfully improve knowledge and safety awareness, sharing in the construction sector, and facilitate the reduction of the number of accidents. It also aimed to identify the most popular and commonly used information technology tools by construction practitioners.

Spcifically, we have two research questions for this article:

What are the most convenient and useful information technology tools that can be adopted by construction companies to encourage and ensure the sharing of knowledge and safety awareness with their employees in the knowledge economy?

How can the use of these tools be encouraged (consider influencing factors, motivations and barriers)?

The present study used an evidence-based approach, whereby past and recent literature was reviewed, focusing on three main themes, including the use and popularity of mobile apps, IoT and Web 2.0 in safety knowledge sharing, barriers and motivations affecting this trend, and the psychological and informal institution perspective. Self-administered questionnaires were used to validate the information collected regarding these trends. The target population was international constructional workers. The present paper aims to contribute to this aspect by focusing on the use of various information technology tools to share safety knowledge. It is divided into five sections: an analytical literature review, the research methodology, an analysis of the findings, discussion, and conclusion and recommendations.

\section{Literature review}

The construction process involves workers with diverse skill sets, and millions of people are working in this sector across the globe (Rostami, Sommerville, Wong \& Lee, 2015). Accidents happen inevitably and frequently on construction sites (Carbonari, Giretti \& Nticchia, 2011). A recent research study concluded that the use of enterprise social media is an effective way of knowledge sharing (Pee, 2018), as this will improve connectivity among employees and workers.

The sharing culture is an everyday practice for most people, but the sharing of knowledge from an overall perspective and in an organisational setting is a necessary issue that is considered complicated (Gaál et al., 2015). Knowledge sharing refers to the process whereby the knowledge possessed by one person is converted into a usable form and is comprehensible to another person (Gaál et al., 2015). Indeed, knowledge sharing is vital for any organisation, as it is the foundation of business development through new ideas and innovation, as well as the process by which employees learn (Assegaff et al., 2017). However, the process is determined by the willingness of employees to share the information and consult with colleagues. Gaál et al. (2015) identified four issues that usually influence knowledge sharing: the nature of the knowledge, motivational factors, opportunities available for sharing information and the workplace culture. An additional research study proposed the knowledge sharing platform, which uses the wiki web and ontology approach to facilitate the better communication and representation of construction safety knowledge (Le, Lee \& Park, 2014). It is a challenging task to improve the communication actions based on the information and further knowledge sharing, due to the ad-hoc and subjective nature of construction knowledge among workers (Zhang \& EI-Diraby, 2012).

Information technology provides opportunities for people to share information as well as knowledge. Indeed, various developments in information technology have enhanced the exchange of information, while at the same time factoring out the constraints presented by location, time, and distance (Assegaff et al., 2017). A study conducted by McKinsey and Company revealed some benefits attained by companies that use information technology, especially social media platforms (Nielsen \& Razmerita, 2014), such as increased employee productivity, increased revenue, reduced business costs, and more innovative services and products. Among the various information technology tools, social media has proven the most popular and effective in business, particularly for consumer coverage and product marketing. Indeed, it plays a significant role in the sharing and consumption of news (Kümpel et al., 2015). In recent years, many organisations have paid more attention to the application of information technology, not only for news and marketing, but also for internal organisational improvement via employee communication. The construction sector has not been left behind during this migration towards virtual knowledge sharing.

Several studies have been conducted regarding social media use in knowledge sharing. Gibbs et al. (2013) focused on the usage of social media for knowledge exchange and its effect on behaviour. Despite the tensions in responses associated with the use of Web 2.0, many people in different professions are willing to use these platforms (Gibbs et al., 2013; Majchrzak et al., 2013). Chen and Bryer (2012) noted that there have been global surges in the number of users of social media platforms each year, with Facebook having passed more than 750 million 
users in 2011 alone. However, the quality of information and news shared on such platforms varies, with the circulation of fake news and information being a regular occurrence (Chuang \& Schechter, 2015).

Over the years, social media in knowledge sharing has been proven to be effective in organisations which have adopted these platforms as key communication channels. Most mechanisms are devised to test how people engage in sharing knowledge in an organisation. A research study conducted by Majchrzak et al. (2013) showed that the positive effects were higher than the adverse effects.

The use of mobile apps in promoting safety awareness in construction is useful, as said apps allow even those with low education levels to access knowledge. A good example is the Red Cross app, which prioritises crucial first-responder steps when offering first aid in different situations (Li et al., 2018). The occupational safety and health hazard game is an application that allows workers to enjoy playing in their free time, while they also learn about various safety precaution issues. Instructions are indicated in the game, and minimum tutorials are necessary. Although the research on the use of mobile apps in construction safety is limited ( $\mathrm{Li}, 2015)$, a variety of literature has proven that applications are useful for step-by-step instructions or following procedures while performing a task (Li \& Poon, 2013). This demonstrates their convenience in sharing safety awareness information in any sector.

The willingness to use the IoT for knowledge sharing and safety awareness in the construction practice is crucial ( $\mathrm{Li}$ et al., 2018). Most workers consider the complexity of this technology a barrier to its use, while some are not even willing to try, and rather consider social media as their preferred choice. In recent years, Korea has introduced certain approaches to ensure construction site safety. An example of this is the use of SMS service, whereby workers input their identification codes, supervisor details, and location, allowing the safety officers to respond immediately at the site $(\mathrm{Li}, 2015)$.

Workers must be motivated to share knowledge (Li \& Poon, 2013), and so the ease of use of the technology being applied to share the knowledge can have a significant influence, as many people will give up on complex processes. The convenience of use and convenience of access equally determine the time people dedicate to knowledge mining (Skeepers \& Mbohwa, 2015). Besides this, the organisation should be willing to incur the costs of this valuable possession (Oye et al., 2011) through compensation and incentives such as bonuses, tips, salaries, paid holidays and promotions. Oye et al. (2011) identified some reasons why people may be unwilling to share information, including job insecurity, confidentiality, fear of information causing harm and their general personality traits. All of these listed reasons are individual-centred and will require an alteration of the person's perception of knowledge sharing by the organisation.

According to Panahi et al. (2012), the factors influencing knowledge sharing using information technology include personal characteristics. Li et al. (2018) suggested that the value and success of a proposition are the two major factors that determine if a person is willing to repeat an action. Apart from rewards and incentives as factors affecting the willingness of workers to participate in knowledge sharing, the remainder are psychology-related factors. The exchange relationship created by a superior towards employees is a critical determinant of employee attitudes towards sharing information, especially in high technology firms where the generation of new ideas is potentially in the hands of employees (Skeepers \& Mbohwa, 2012; Assegaff et al., 2017). The internal actualisation of employees is achieved when there is perceived organisational support and acknowledgment. An organisation portrays value for the commitment of the employees as well as concern for their wellbeing, motivates the employees to work for the betterment of the organisation (Belay, 2016).

The differences in age and cultural backgrounds affect the willingness of workers in the construction industry to share knowledge (Ahmad et al., 2013; Ding et al., 2018). These differences also influence the selected channel of communication (Fang \& Fong, 2010). Li et al. (2018) contended that various age groups have different opinions on sharing knowledge via mobile applications, the IoT and Web 2.0, which also determines their preferred choice. The baby boomer generation prefers to use phone communication and their interest in using current technology is also limited, whereas those born after the baby boomers (1965-1980), commonly referred to as generation $\mathrm{X}$, have more interest in technology. Besides, generation $\mathrm{Y}$ construction workers are ready to use complicated devices. Finally, ethnicity and cultural differences also influence the type of knowledge that people are willing to share (Li et al., 2018).

\section{Research method}

Thematic content analysis was used to scrutinise the literature selected, as this allows for the grouping and categorising of similar information to create and communicate a clear common objective $(\mathrm{Li}, 2016)$ based on identifying themes related to knowledge sharing and safety awareness using information technology. The selected articles were freely accessible from different online databases, with most of the articles authored in developed countries or technologically-able to developing countries. A thorough qualitative analysis was conducted in the literature review section to justify similarities and differences in the opinions of different researchers.

Comprehensive questionnaires were used to conduct an online survey via LinkedIn and Facebook to collect data. The poll focused on issues concerning the application of information technology tools in knowledge exchange and influencing factors (see Appendix 1). Most questions adopted the Likerttype format approach, where participants were expected to respond to statements using the Likert scale. The sample population consisted of randomly selected international construction practitioners based on their willingness to participate. A quantitative analysis was adopted for analysing the surveys. 


\section{Results}

The sample population consisted of both genders, although predominately men, with women representing approximately one third of the group. This reflected the male-dominated industry in many countries around the globe. Among the 519 questionnaires, the experience of the workers ranged from 1 to 37 years. Gender, experience, and level of education did not have a significant effect on work-related responses.

In total, $52 \%$ of the respondents had used Web 2.0 to share construction safety information without specifying which platform they had used. Most respondents (68\%) agreed that age was a hindrance to the application of Web 2.0 in sharing information, probably because the respondents were of different ages. Moreover, 6\% remained neutral in this aspect. Similarly, more than $53 \%$ of the participants considered the lack of technical skill as a barrier to using the platforms, with $67 \%$ viewing convenience as a critical motivation for using social media. Concerning incentives and rewards, 38\% disagreed that they regarded them as motivational aspects.

Mobile applications were found to be less popular among the professionals, with only $43 \%$ of the participants reporting that they had used mobile apps for information sharing in communication. The majority of these held senior professional positions in the sector, while most of those who had not used mobile apps had a lower level of education and an advanced age. Irrespective of this, most participants were willing to use mobile apps to share safety knowledge, the majority of whom were above 50 on the $0-100$ scale. Only $28 \%$ of the respondents agreed that their lack of knowledge of using mobile apps was the main barrier for them. Regarding the older generation and use of mobile apps, $47 \%$ considered it an obstacle. This trend can be justified by the different age groups in the sample population and generally in the construction sector. Mobile apps scored equally to social media concerning convenience. The fact that mobile apps can be used anywhere and anytime was considered a motivation for sharing of knowledge using such technology by $39.2 \%$ of the participants. There was a sizeable proportion of participants who were neutral regarding this issue.

The IoT was the least popular of the three information technology tools, scoring an average of 40 on the scale of 0 100 for willingness to use the IoT, with only $19 \%$ of the participants having used it to exchange construction safety information. Further analysis of this small population of users revealed that country of origin was a determinant; for instance, almost all top ranked workers in the sector from Hong Kong working for companies ranked 200 or above had used this technology. This reveals that job position, education level and the general technological development of a country influenced the use of IoT. In this case, many agreed that inadequate knowledge of IoT was a crucial barrier to knowledge sharing using this platform. Regarding privacy concerns as a barrier to using IoT, many participants remained neutral in their opinion. The participants showed determination in using the IoT for sharing safety information, with $67 \%$ of respondents agreeing that their motivation for using the IoT was to create awareness, while only $21 \%$ disagreed with the notion that knowledge sharing is a motivation. In contrast, Web 2.0 was the most popular tool and had the highest number of users (see Fig. 1).

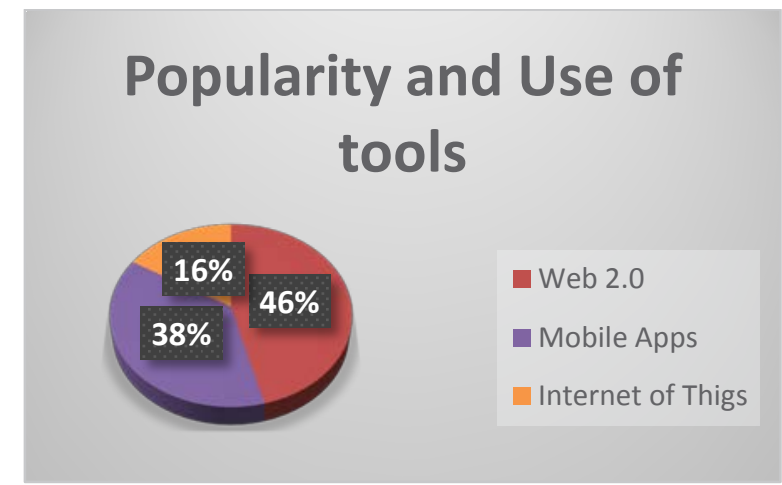

Fig. 1. The popularity and use of information technology tools among construction practitioners.

Based on the 0-100 scale, the organisation's concern for employee safety and the valuing of employees' contribution scored an average of above $50 \%$, revealing the positive relationship between the workers and their superiors. Most employees appreciated their bosses and supervisors, and valued the everyday tasks assigned to them. This motivated the employees to do more than required, both for the company and to please their bosses. Only $37 \%$ of the participants disagreed with the notion that they committed themselves to doing more than was required.

A total of $58 \%$ of the respondents would be more willing to participate in the sharing of information for rewards. Monetary rewards, including salary increments and bonuses among others, were the most preferred. The number of accidents experienced by the workers showed direct interdependence with age and worker's profession. There are certain jobs which are riskier than others in the construction industry, and thus onsite workers with more years of experience reported a higher number of near misses and witnessing accidents while working, which is why knowledge sharing is essential. A unique trend identified from the questionnaires was the knowledge of existing information technology platforms (either Web 2.0, mobile applications or the IoT), whereby only workers from developed countries, including Germany, France, the UK, the US, Canada, and New Zealand, had encountered them. Others who knew of such tools were from technology giants in developing economies such as China, Hong Kong, and Korea.

The literature review agreed with the findings of this research, with $99 \%$ of the articles analysed agreeing that information technology is useful in sharing knowledge across all industries. In total, $13 \%$ considered privacy concerns an issue on the online social media platforms, but this did not deter their willingness to use these platforms. Similarly, it was found that a lack of knowledge of the older generation regarding the use of various platforms was a significant challenge for 
information sharing. The determination and willingness to learn have, however, led to increased use of these platforms, with $54 \%$ of the articles regarding knowledge sharing confirming this. The financial constraint was a barrier experienced by $67 \%$ of low-income countries with underdeveloped or developing economies. The popularity of mobile applications for knowledge sharing and safety awareness was below $40 \%$ in these countries. In addition, the use of the IoT was below $35 \%$ in many countries, with its use prevailing in the developed economies according to the research. $78 \%$ of the articles highlighted the need for motivation to encourage knowledge sharing. There were few open access articles regarding the construction industry, although those available showed that knowledge sharing could reduce the number of accidents in the sector. To achieve this, the management of the companies must assume the responsibility of educating and encouraging the workers to accomplish said task.

\section{Discussion}

The high levels of risk involved and the increasing number of accidents in the construction industry have raised the need to devise strategies that will deal with the situation. According to $\mathrm{Li}$, most construction accidents are caused by worker-centred issues ( $\mathrm{Li}, 2016$ ), with the highest number of accidents caused by immediate, direct factors, including slips and object slips, falling objects and falls from heights. Such situations happen, especially when the worker is not familiar with the site or is not aware of new changes (Carbonari et al., 2011), or if there is a lack of safety education and training, relational or communication problems, as well as human error (Li, 2016). The safety behaviours of workers (Ahmad, 2013), unsafe acts, and attitudes (Fang et al., 2006) increase the likelihood of accidents, and thus improving the knowledge of the workers will help to reduce the risk of accidents.

Sharing of knowledge is a critical strategy that can help improve safety in the construction industry (Ding et al., 2018; Fang \& Fong, 2010; Li, 2015). In her research on construction safety via mobile phone apps, Li found that the construction sector makes minimal use of information technology for knowledge sharing and safety advice (Li, 2016). Indeed, the use of information technology, especially social media, has been scarce in providing safety information for the building process, as evidenced by the findings of this research, where only $52 \%$ of the respondents stated that they have used social media platforms to share construction safety knowledge and awareness, despite them being the most popular online communication platforms today.

One of the reasons identified from the research was the age difference. The construction sector is the second industry after agriculture where manual jobs involve more craft and experience with less education. Only a few construction professionals are required on-site, with the remainder consisting of manual workers; indeed, this explains why social media is less popular among construction workers compared to other sectors, such as medicine and nursing, which are slowly doing away with face-to-face meetings for knowledge sharing. The content of information determines its popularity (Kümpel et al., 2015), with political and celebrity news being most prevalent in social media. Safety awareness receives considerable attention, especially when it is medical in nature (Gressgard, 2014). In the construction industry, knowledge sharing is only related to practitioners ( $\mathrm{Li}$ et al., 2018), although it is enough for sharing valuable knowledge and safety awareness to reduce accidents.

The inability of the old, who are still working based on experience, is a significant hindrance to the use of social media platforms (Kümpel et al., 2015; Chuang \& Schechter, 2015). Consequently, and as noted by Li et al. (2018), this breaks the communication and knowledge sharing; dissemination and access to knowledge as well as safety awareness are not complete, thus promoting the inadequacy of the workers. Nonetheless, mobile phone applications, though less prevalent in the construction sector, are most effective in demonstrating safety awareness as well as sharing knowledge. In today's world, ownership of a mobile phone, especially a smartphone, is considered a necessity. Global research on social media by Chaffey (2016) found that a total of 5.135 billion people were using mobile phones in 2018 - a number that increases by $4 \%$ each year. This shows the possibility of $98 \%$ of construction workers owning mobile phones, and therefore mobile apps may be easier to use compared to social media, considering the nature of the knowledge to be transmitted (Li, 2015). Indeed, mobile phones can be instrumental in safety awareness compared to other information technology tools.

The use of the IoT is becoming increasingly popular. The IoT has recently been used to provide warnings of unsafe conditions to employees at their workplace. Installed devices will raise the alarm when perceived danger is sensed. These devices have also reduced and significantly improved situations often prone to accidents triggered by human error, and so they could be applied in the construction sector, where human error is among the highest causes of accidents. Additionally, the IoT stores databases containing valuable information which can be used in emergencies, helping to deal with emergent situations, as knowledge can be accessed through these devices. Moreover, these databases enhance safety awareness to a reasonable degree. However, a key barrier associated with the use of the IoT is knowledge of workers, as many are not familiar with this technology, and it is only evident in developed and some developing countries.

It is the responsibility of the organisation to motivate the workers and treat knowledge management as a primary objective in its overall goals. To apply these technological approaches to knowledge sharing and the promotion of safety awareness, the organisation needs to remove all possible barriers that hinder or slow down the process. To further overcome such barriers, key motivating factors can be used to promote knowledge sharing, such as providing the necessary technology or the use of incentives and rewards. Further appreciation of the information shared increases the need to provide more valuable information. A worker will need to know that the organisation appreciates their efforts in sharing knowledge. Sharing information to earn money or build good 
relationships is not the reason why workers may want to share their experience (Oye et al., 2011); the need to feed their esteem increases, while self-actualisation acts as an umbrella to all of this. The satisfaction that is derived from being helpful and saving lives, even without any rewards, is more prevalent. As evident in this study, a high percentage of the respondents considered the need to share knowledge as a motivational factor itself.

Informal institutions influence the aspect of knowledge sharing and construction safety awareness in the knowledge economy, and its connection with social media cannot be ignored (Chen $\&$ Bryer, 2012). Members of the younger generation are aware of their rights as well as other safety issues in the sector, such as the company's responsibilities in providing their safety. This proves that the age difference influences knowledge sharing. The support or facilitation availed by the government promotes and motivates workers to share knowledge. The research findings showed that the presence of applications or IoT for knowledge exchange or safety awareness in construction was influenced by the overall development level of the country. Most countries where practitioners have used such technology are the most significant world economies, such as Germany, France, the UK, Canada, and the US, thus indicating that technological developments in construction safety are a constituent of the economic events in the country. Developing economies, where technology is among the leading contributors, also have such applications.

\section{Conclusion}

Knowledge sharing and construction safety awareness are essential in reducing the number of fatalities and losses experienced in the construction industry as a result of accidents. The current popularity of Web 2.0 is an opportunity to enhance valuable information sharing. Social media platforms have proven effective in spreading news and awareness in other sectors, and thus can be applied by the construction sector. The advantage of such platforms is that privacy concerns are protected, and any personal information revealed is in the power of any individual, which is the same for mobile applications. Mobile apps are useful in raising construction safety awareness and can be designed and customised by the company for use by all employees. Today, many organisations provide smartphones and personal computers to their employees to facilitate their work, which can also be used for promoting safety.

Barriers and motivators are critical determinants of the quality and amount of knowledge shared by workers. Indeed, accidents caused by factors such as moving and falling objects on-site can be prevented by sharing the necessary expertise, such as the equipment to use or the route to use on the site as well as creating prior awareness regarding a dangerous situation; as such, instant communication is a significant challenge in the construction business. It has proven difficult for workers to use mobile phones and computers on-site. However, this can be overcome by the commissioning of safety specialists to continuously assess sites, and update any hazardous regions or activities on Web 2.0, which is more popular and easily accessible for many workers, thereby circulating information quickly to prevent accidents.

Organisations are also responsible for the psychological welfare of their employees. Recognition of efforts by workers is a crucial motivator identified by human resource specialists. Money and other non-monetary benefits should also be provided as a form of appreciation. Most importantly, maintaining a valuable relationship with the workers is essential in promoting knowledge sharing among them and even with the management. Recognition is important for selfactualisation needs and should be used regularly. To some extent, informal institutions may also influence the exchange of knowledge. Government support might help in this regard to reduce the number of accidents related to human error.

Web 2.0, the IoT and mobile applications are information technology tools that have the potential to reduce risks and errors in the construction industry. It is anticipated that the application of such technology, with the necessary support from governments, will help to improve operations in this sector, concurrently promoting the wellbeing of the construction workers. Invention and development of such technologies are expected to increase in the future, and it will be beneficial for companies to move with these changes. Therefore, it is recommended that construction companies implement knowledge management strategies to enhance knowledge sharing, using the most up-to-date information technology tools; indeed, they can facilitate this process by ensuring that their employees have the necessary gadgets, such as smartphones.

Furthermore, maintaining good relationships with the workers should be prioritised by the company. This will encourage communication and result in knowledge sharing. The organisation should also consider incentives and rewards to motivate employees. Psychological comfort and satisfaction can be perceived by the workers when they are valued, and their effort acknowledged. In this way, they will be willing to work towards the improvement of the company, which includes knowledge sharing.

\section{Acknowledgement}

This paper is supported by Research Grant Council Competitive Research Funding Schemes for the Local Selffinancing Degree:

Ocular behaviour, construction hazard awareness and an AI chatbot, UGC/FDS15/E01/18

Willingness to share construction safety knowledge via Web 2.0, mobile apps and IoT, RGC grant, UGC/FDS15/E01/17 


\section{References}

\section{Journal articles}

Ahmad, S.S., Isnin, Z., Yahya, Z. and Salleh, M.M., 2013. Knowledge sharing of research information for construction health and safety practices. Procedia-Social and Behavioral Sciences, 105, pp.239-248.

Assegaff, S., Kurniabudi, K. and Hendri, H., 2016. Social Media Success for Knowledge Sharing: Instrument Content Validation. International Journal of Electrical and Computer Engineering (IJECE), 6(5), pp.2447-2453.

Belay, A.M., Torp, O. and Thodesen, C., 2016. Managing Concurrent Construction Projects Using Knowledge Management and Set-based Thinking. Procedia Engineering, 164, pp.235-242.

Carbonari, A., Giretti, A. and Naticchia, B., 2011. A proactive system for real-time safety management in construction sites. Automation in Construction, 20(6), pp.686-698.

Chen, B. and Bryer, T., 2012. Investigating instructional strategies for using social media in formal and informal learning. The International Review of Research in Open and Distributed Learning, 13(1), pp.87-104.

Chuang, Y. and Schechter, L., 2015. Social networks in developing countries. Annu. Rev. Resour. Econ., 7(1), pp.451472.

Ding, L.Y., Zhong, B.T., Wu, S. and Luo, H.B., 2016. Construction risk knowledge management in BIM using ontology and semantic web technology. Safety Science, 87, pp.202-213.

Fang, D., Chen, Y. and Wong, L., 2006. Safety climate in construction industry: a case study in Hong Kong. Journal of construction engineering and management, 132(6), pp.573-584. Fang, Y., Cho, Y.K., Durso, F. and Seo, J., 2018. Assessment of operator's situation awareness for smart operation of mobile cranes. Automation in Construction, 85, pp.65-75.

Gaál, Z., Szabó, L., Obermayer-Kovács, N. and Csepregi, A., 2015. Exploring the role of social media in knowledge sharing. Electronic Journal of Knowledge Management, 13(3).

Gibbs, J.L., Rozaidi, N.A. and Eisenberg, J., 2013. Overcoming the "ideology of openness": Probing the affordances of social media for organisational knowledge sharing. Journal of Computer-Mediated Communication, 19(1), pp.102-120.

Gressgård, L.J., 2014. Knowledge management and safety compliance in a high-risk distributed organisational system. Safety and Health at Work, 5(2), pp.53-59.

Le, Q.T., Lee, D.Y. and Park, C.S., 2014. A social network system for sharing construction safety and health knowledge. Automation in Construction, 46, pp.30-37.

Li, H., Chan, G., \& Skitmore, M. (2012). Visualizing safety assessment by integrating the use of game technology. Automation in Construction, 22, 498-505.

Le, Q. T., Lee, D. Y., \& Park, C. S. (2014). A social network system for sharing construction safety and health knowledge. Automation in Construction, 46, 30-37.

Musonda I. \& Smallwood J. (2008) Health and safety (H\&S) awareness and implementation in Botswana's construction industry. Journal of Engineering, Design and Technology 6, 81-90.
Jeelani, I., Albert, A. \& Gambatese, J.A. (2017) Why Do Construction Hazards Remain Unrecognized at the Work Interface? Journal of Construction Engineering and Management 143, 04016128.

Kümpel, A.S., Karnowski, V. and Keyling, T., 2015. News sharing in social media: A review of current research on news sharing users, content, and networks. Social Media+ Society, 1(2), p.2056305115610141.

Majchrzak, A., Faraj, S., Kane, G.C. and Azad, B., 2013. The contradictory influence of social media affordances on online communal knowledge sharing. Journal of Computer-Mediated Communication, 19(1), pp.38-55.

Oye, N.D., Salleh, M. and Noorminshah, A., 2011. Knowledge sharing in workplace: motivators and demotivators. International Journal of Managing Information Technology, 3(4), p.71.

Panahi, S., Watson, J. and Partridge, H., 2012. Social media and tacit knowledge sharing: Developing a conceptual model. World Academy of Science, Engineering and Technology, (64), pp.1095-1102.

Pee, L. (2018). Affordances for sharing domain-specific and complex knowledge on enterprise social media. International Journal of Information Management, 43, 25-37.

Rostami, A., Sommerville, J., Wong, I. L., \& Lee, C. (2015). Risk management implementation in small and medium enterprises in the UK construction industry. Engineering, Construction and Architectural Management, 22(1), 91-107.

Zhang, J \& El-Diraby, T 2012, 'Social semantic portal for coordinating construction communication', J. Comput. Civ. Eng., vol. 26, no. 1, pp. 90-104.

Zeuwts, L.H.R.H., Vansteenkiste, P., Deconinck, F.J.A., Cardon, G. \& Lenoir, M. (2017) Hazard perception in young cyclists and adult cyclists. Accident Analysis \& Prevention 105, 64-71.

\section{Books}

Chaffey, D., 2016. Global social media research summary 2016. Smart Insights: Social Media Marketing.

Li, R.Y.M. and Poon, S.W., 2013. Using Web 2.0 to share the knowledge of construction safety as a public good in nature among researchers: The fable of economic animals. In Construction Safety (pp. 81-95). Springer, Berlin, Heidelberg. Li, R.Y.M., 2016. Construction Safety and Waste Management. Springer.

Li, R.Y.M., 2015. Construction safety knowledge sharing via smartphone apps and technologies. Handbook of Mobile Teaching and Learning, pp.1-11.

Nielsen, P. and Razmerita, L., 2014, June. Motivation and knowledge sharing through social media within Danish organisations. In International Working Conference on Transfer and Diffusion of IT (pp. 197-213). Springer, Berlin, Heidelberg.

Skeepers, N.C. and Mbohwa, C., 2015. A study on the leadership behaviour, safety leadership and safety performance in the construction industry in South Africa. 


\section{Conference paper}

Diamond S (1993) The mechanisms of lithium effects. Proceedings of the 9th International Conference in Reaction Concrete, London (Bloggs J and Smith JA (eds)). Applied Science, London, UK, vol. 1, pp. 69-78.

Fang, D., Huang, J. and Fong, P.S.W., 2010, May. Sharing construction safety knowledge through social networks. In W099-Special Track 18th CIB World Building Congress.

Li, R.Y.M., Chau, K.W., Ho, D.C.W., Lu, W., Lam, M.W.Y. and Leung, T.H., 2018, June. Construction safety knowledge sharing by Internet of Things, Web 2.0 and mobile apps: psychological and new institutional economics conceptual analysis. In IOP Conference Series: Materials Science and Engineering (Vol. 365, No. 6, p. 062042). IOP Publishing. Reynolds GC and Beeby AW (1982) Bond strength of deformed bars. Proceedings of the 2nd International Conference on Bond in Concrete, Paisley. Applied Science, London, UK, pp. 434-445. 